\title{
Vikrant Rana: The Publisher's Law Book: A Dependable Work for Ready Reference
}

\section{Federation of Indian Chambers of Commerce and Industry, Federation House, Tansen Marg, New Delhi 110001, India, 2013, 118 pp, paperback}

\author{
Manish Arora
}

Published online: 9 April 2014

(C) The Author(s) 2014. This article is published with open access at Springerlink.com

Books are words frozen in time for eternity to ensure that the wisdom or information they carry is not lost to the natural erosion that the never-ceasing stream of time unleashes on everything else. Publishing an article or a book is an act of preservation, an exercise in immortalization, so to speak. But to keep the publishing industry running and the writers writing, it has to be ensured that a suitable environment conducive to writing and publishing is provided, promoted and sustained by protecting Intellectual Property Rights (IPRs) against unscrupulous encroachment. This is where law steps in.

It goes without saying that the most effective protection against infringement of IPRs stems from a vigilant approach on part of the creators, innovators, designers and writers. Books like Publisher's Law Book by Vikrant Rana go a long way in ensuring that those whose rights are at stake are not only aware of their rights but are also sure of the best course available to them in case their rights as creators are infringed.

What is remarkable about the book is that, despite having been written by a legal professional, it is not legalistic, which makes it possible for a general reader to benefit from the book just as much as a specialist might. The work is doubtlessly very informative, but that is not the only good thing about it. The information has been arranged in a manner that is conducive for quick reference and easy reading.

The very first chapter of the book introduces us to the history and evolution of publishing industry in India, and one can glance through it to have a good understanding of how the publishing industry in India evolved from 'tamrapatra', 'tadapatra', 'lohapatra' and 'bhojpatra' eras of publishing to the times of Amazon Kindle and the marketing and distribution revolution of Flipkart. The chapter also casts sufficient light on the future of publishing industry in India and where it stands on the world publishing scene.

M. Arora $(\bowtie)$

F 21 Model Town, New Delhi 110009, India

e-mail: manish@justice.com 
After providing the reader with a good understanding of where the publishing industry in India began from and where it has come to, the book takes one to the legal and regulatory framework within which the publishing industry of the country operates. After touching the legal history of the laws relating to publishing briefly, the second chapter gives us a quick walk through the legal provisions that govern publishing in India. But it stops short of discussing how to protect and manage one's IPRs, which is the subject matter of the third chapter, where it is discussed in great detail starting from what is an IPR and why it needs to be managed, to trademarks and copyright protection and the legal remedies available in case of infringement. Another admirable thing about the book is that the author ensured that the issues are dealt with not only from the Indian perspective, but the reader also gets a sufficiently sound understanding of the global view of the issues and concepts under discussion.

As indicated above, the book is not legalistic, thankfully. So, we have a chapter that gives us useful statistics related to publishing industry in India. And the author has not simply thrown raw, near-incomprehensible data at us, but has taken pains to analyze it and derive useful conclusions to help the reader understand with sufficient clarity as to what shape Indian publishing industry is taking.

Furthermore, the need for associations to take care of the publishing industry and take collective steps for the betterment of the entire industry is also not lost on the author. This is why the book not only enlists the relevant associations, but also provides adequate information about them so that the publishers could actually use the information instead of it simply lying between the pages of the book for an academic researcher to find. The emergence of digital publishing as an alternative model has also been paid due attention by the author and an entire chapter has been devoted to digital publishing and the protection of IPRs vested in the content published and circulated digitally. Furthermore, the book also touches the collective management of copyrights and reprographic rights through intermediary agencies, which is basically a means to make it possible and practicable for the individual authors and creators to protect their rights against large-scale violations.

With the Indian publishing industry thriving like never before there is a growing need for books like the Publisher's Law Book, which is not a book for leisurely, pleasure reading, but is a handbook meant to be part of a publisher's personal library to be used for the purpose of ready reference because it supplies the requisite information in a extremely well-structured format, which is very well suited for those times when one needs a handy guidebook to provide a dependable start to a problem-solving Endeavour.

Open Access This article is distributed under the terms of the Creative Commons Attribution License which permits any use, distribution, and reproduction in any medium, provided the original author(s) and the source are credited. 